\title{
Cardiology
}

\section{Differences Between Expressive Suppression and Cognitive Reappraisal Between Heart Disease and General Population}

\author{
Seyyed Mohammad Reza Mirlohi ${ }^{1}$, Banafsheh Mohajerin², \\ Seyyed Mohammad Javad Mirlohi ${ }^{3 *}$, Nasrin Mohammadi Aref ${ }^{3}$ \\ ${ }^{I}$ Cardiology Department. Jamaran Heart Hospital \\ ${ }^{2}$ Psychology Department. University of Social Welfare and Rehabilitation Sciences \\ ${ }^{3}$ Medical Student Research Committee, Tehran Medical Sciences Branch, Islamic Azad University \\ Tehran, Iran
}

\begin{abstract}
Aim: Heart disease and emotional disorders often co-occur, but effective role in dysregulation of heart disease that is often overlooked. Evidence suggests that people with heart disease are more problems in regulating their emotions.

The study compared the re-evaluation of cognitive emotion regulation commonly used two strategies- and suppressionbetween heart disease and the general population.

Methods: Sixty men (30 with heart complaints and 30 without the condition) were selected by convenience sampling method and they responded to the Emotion Regulation Questionnaire (Gross and John) and a demographic questionnaire responded. To analyze the results and descriptive statistics such as frequency tables and inferential statistics, independent T-test was used SPSS software was used.

Results: The result shows that heart disease and general population re-evaluation strategies groups $(\mathrm{P}<0.01)$. This is not only different from the strategy reassessment, but in different repression, too. $(\mathrm{P}<0.001)$.

Conclusion: The results showed that heart disease and general population used different strategies to regulate their emotions. The key to finding the heart disease group prefer repression to regulate their emotions.(International Journal of Biomedicine. 2017;7(3):192-195.)
\end{abstract}

Key Words: emotional regulation $\bullet$ expressive suppression $\bullet$ reappraisal $\bullet$ heart diseases

\section{Background and Aim}

In recent years evidence of the importance of psychological factors in the development and progression of cardiovascular disease..$^{(1)}$ Based on last report heart disease is a major cause of thirty eight percentages of death in the last year in Iran, and 15 million deaths in the world were based on this disease. ${ }^{(2)}$

Traditional risk factors (such as smoking, hypertension, hypercholesterolemia, obesity and diabetes) only about $40 \%$ incidence of coronary heart disease. ${ }^{(3-4)}$ Although the relationship between emotions and heart has been hypothesized for many centuries, until recently, there was no convincing evidence for such relationships. Evidence that specific emotions such as depression, anxiety and stress as a major potential risk factors for coronary heart disease show appearance..$^{(5-8)}$

*Corresponding author: Seyyed Mohammad Javad Mirlohi Medical Student Research Committee, Tehran Medical Sciences Branch, Islamic Azad University, Tehran, Iran.E-mail:mj.mirlohi@gmail.com
Emotions on cardiovascular health through multiple pathways may influence the specific ways of activation of the sympathetic nervous system or the Hypothalamic-PituitaryAdrenocorticol (HPA) axis. ${ }^{(9-10)}$ Evidence shows special association between heart disease and specific negative emotions: depression,anxiety and anger.

Empirical and anecdotal evidence indicated a relationship between negative affect and heart disease. This relationship is the concept that people experience higher levels of negative as at higher risk from the use of coping mechanisms such as drugs, food or alcohol to escape from the experience of these emotions. ${ }^{(11)}$

Theorists and researchers have been defined in a different way from concept to regulate emotions. Most definitions penetrated by Gross (1998), "The process by which individuals influence their emotions, when they are, and how they experience and express these emotions." ${ }^{(11)}$ Thompson it is defined as internal and external processes responsible for monitoring, evaluating and modifying emotional reactions, especially intensive features and your time, to achieve one's goals." (12) 
People use different strategies to change their emotions. This strategy not only affect their current emotional experience, but also in interpersonal and cognitive process, too. Emotion regulation is regarded as a crucial factor in wellbeing and adaptive behavior and there are different strategies which individuals use for this purpose, but as Garefski (2002) argued some of these strategies are more adaptable than the others. ${ }^{(13)}$ Two well-studied strategy to re-evaluate emotional regulation and suppression ${ }^{(14)}$ to reduce (or increase) the tendency of emotional response or affective states. ${ }^{(15)}$ Suppress emotionally-expressive behavior inhibition in emotional arousal decreases. ${ }^{(16)}$ Re-evaluation reinterpretation of emotional stimuli valenced in and emotionless. ${ }^{(17)}$ This includes the production of interpretation and perspective benign or positive in a stressful situation as a way to reduce distress. ${ }^{(18)}$ Reassessment may be particularly important for psychopathology have good feelings and beliefs about who they are. ${ }^{(19)}$ Both reappraisal and suppression of negative emotional stimuli can reduce the effect.

\section{Objectives}

The aim of this study was to investigate differences in emotion regulation between heart disease patients and general population.

\section{Patients and Methods}

\section{Participants}

This population consisted of patients diagnosed with heart disease, Participants were 60 men,30 inpatients with heart disease complain from Jamaran and Milad hospital in Tehran,Iran and control group include 30 men of patient's relatives but without having any heart disease history,these groups were selected by accessible sampling. The sample ranged in age from 42.16 years old (mean). Data collected between October and December of 2014. Demographic information be shown in Table 1.

Table 1.

Demographic characteristics of inpatient and control groups

\begin{tabular}{|l|c|c|}
\hline & $\begin{array}{c}\text { Inpatient } \\
\text { No, }(\%)(\mathrm{n}=30)\end{array}$ & $\begin{array}{c}\text { Control } \\
\text { No. }(\%)(\mathrm{n}=30)\end{array}$ \\
\hline Education & & \\
\hline Elementary & $2(6.8)$ & $4(13.3)$ \\
\hline Guidance school & $4(13.3)$ & $2(6.7)$ \\
\hline High school and more & $24(80)$ & $24(80)$ \\
\hline AGE & & \\
\hline $27-35$ & $9(30)$ & $7(23 / 3)$ \\
\hline $36-44$ & $10(33.3)$ & $9(30)$ \\
\hline $45-53$ & $7(23.3)$ & $11(36.7)$ \\
\hline $54-62$ & $4(13.3)$ & $3(10)$ \\
\hline Marital Status & & $6(20)$ \\
\hline Single & $8(26.7)$ & $18(60)$ \\
\hline Married & $16(53.3)$ & $6(20)$ \\
\hline Divorced & $6(20)$ & \\
\hline
\end{tabular}

\section{Procedure}

Sixty individual (Thirty heart disease inpatient men and 30 men without heart disease history were selected by accessible sampling from Jamaran and Milad Hospital in Tehran, Iran. Eligible participants have said they are under no obligation to participate in the study, although they encourage them to do it. Initially, participants with a face to face interview using a demographic questionnaire was provided demographic information. This information included age, marital status and education level. They described their age,education and marital status. They were rested for 10 minutes, then they were asked to fill in Emotion Regulation Questionnaire (ERQ) by Gross and John with a series of 10 statements. The ERQ evaluation typical of suppressed emotions (4 items, eg,." I keep my emotions to myself) and reassessment (6 items, eg.,'When I want to feel less negative emotion, I change the way I'm thinking about the situation) in person. They sitting separately in completing the questionnaire. The collected data were analyzed by SPSS 16 software and inferential statistics, independent T-test used to the analysis the data.

\section{$\underline{\text { Measures }}$}

Emotion Regulation Questionnaire ${ }^{(20)}$ to assess individual differences in the habitual use of the style is designed in emotion regulation include cognitive reappraisal and suppression. Cognitive reappraisal (When I want to feel more positive emotion, I change the way I'm thinking about the situation) and suppression (I keep my emotions to myself). The questionnaire consisted of 10 items, of which four suppress evaluation and re-evaluation of the six appraisal strategy. Asked participants to rate how they regulate their emotions using a scale of 1 to 7 , a higher score indicates more individual use strategies to regulate their emotions. Secondary points around the items for each scale were calculated in variable form of repression and re-evaluation. Gross and John (2003) reported Cronbach $\alpha$ reliability coefficient value of 0.79 and 0.73 for re-evaluation and test-retest reliability for suppressing $=0.73$ in 3 months $=0.69 .^{(20-21)}$ In this study the Persian translation of ERQ were used to estimate the internal consistency Cronbach's alpha coefficient was 0.83 for reassessment 0.68 for repression.

\section{Demographic questionnaire}

Three factor age,education and marital status were asked by sample demographic questionnaire which was designed just for this study. This information was asked for norming these group by their age and educational levels.

\section{Data analysis}

SPSS 16, descriptive statistics such as frequency tables and inferential statistics such as T-test was used. This study performed on 60 men (30 Heart disease inpatient, 30 as a control group). In terms of marital status, 14 subjects $(23.3 \%)$ were single, $34(56.7 \%)$ were married and $3(12 \%)$ were divorced. Average level education was of about 11.45 years $(\mathrm{M}=11.45 ; \mathrm{SD}=0.99)$. The level of education of the participants were as follows: 10\% Max was an elementary school diploma, $10 \%$ of middle school diploma, $48 \%$ had a high school or higher education. 


\section{Result}

\section{Group comparisons}

The result shows the two groups has no significant differences in age, education

The result indicates that the patient and control groups reassess the strategy is different. After re-evaluation in the control group showed significantly higher scores. Thus it appears that they usually use this strategy to adjust their emotions.

These groups are not only differs from the strategy of reassessment, but the suppression, too. As a result of that in Table 2, these groups is different in using your habitual the suppression. It appears inpatient group to use this strategy to adjust their emotions.

Table 2.

Comparing age and education between inpatient heart disease and control population $(p=0.01)$

\begin{tabular}{|l|c|c|c|c|c|c|c|}
\hline & & $\mathrm{N}$ & Mean & $\mathrm{SD}$ & $\mathrm{Df}$ & $\mathrm{T}$ & Sig (2. tailed) \\
\hline \multirow{2}{*}{ AGE } & Inpatient & 30 & 42.16 & 8.87 & \multirow{2}{*}{58} & \multirow{2}{*}{0.063} & 0.95 \\
\cline { 2 - 6 } & Control & 30 & 42.3 & 7.57 & & & \\
\hline \multirow{2}{*}{ EDUCATION } & Inpatient & 30 & 11.73 & 3.02 & 58 & $0 / 72$ & 0.47 \\
\cline { 2 - 5 } & Control & 30 & 11.16 & 3.06 & & & \\
\hline
\end{tabular}

Table 3.

Description and the results of the t test in emotional regulation strategies between patients and control groups

\begin{tabular}{rcccccc}
\hline & $\mathrm{N}$ & Mean & $\mathrm{SD}$ & $\mathrm{T}$ & $\mathrm{Df}$ & $\begin{array}{c}\text { Sig } \\
\text { (2. tailed) }\end{array}$ \\
\hline REAPPRAISAL Inpatients & 30 & 16 & 1.8 & -20.06 & 58 & 0.00 \\
Control & 30 & 27.9 & 2.6 & & & \\
Inpatient & 30 & 18.46 & 2.33 & 19.25 & 58 & 0.000 \\
SUPPRESSION Control & 30 & 11.63 & 2.8 & & & \\
\hline
\end{tabular}

\section{Discussion}

\section{Summary of Findings}

The purpose of this study emotion regulation strategies (reassessment and suppression) in heart disease and general population. Results indicated that patients with heart disease and the control group used various strategies to adjust their emotions. This was a key finding, heart disease patients is prefer suppression and control group usually use reappraisal for this purpose.

Evidence shows that negative emotion such depression,anger and anxiety have different effect on heart disease. For instance, acute anxiety states may hyperventilation, which may cause to hyperventilation which then may cause coronary vasospasm. ${ }^{(23)}$ It is assumed that the acute hemodynamic stress caused severe emotional states of atherosclerotic plaque rupture after acute coronary events, including sudden cardiac death started. ${ }^{(24)}$

As to acute consequences of emotional regulation strategies,reappraisal successfully reduces the negative emotion and increased positive affect,but suppression seems to be ineffective, it may decreased positive affect, increased physiological arousal, or memory impairment. ${ }^{(25)}$ In addition, signs of re-evaluation, but there is not suppression, optimal long-term consequences for the well-being and interpersonal functioning. ${ }^{(26)}$ Memedovic and et al (2010) found that greater dispositional reliance on reappraisal and decreased blood pressure following an stimulating anger, ${ }^{(27)}$ the findings is According to Mauss and colleague (2007) They found that people reassessment of trait anger were reported less frequently and cardiovascular responses more consistent for stimulating than those low in re-evaluation of property. ${ }^{(28)}$ furthermore, reappraisal seemingly helps reducing negative affect. ${ }^{(29)}$

The study may not generalize to specific heart complication. The study relied on self-reported estimates of emotional regulation and the nature of the obstacles conclusions about the impact of the difference reassessment / suppression in this group. Another aspect of future research could examine dysregulation of emotion in this population.

\section{Conclusion}

There is not any assurance that people would not experiencing negative affect in their life but their confrontation with this effect has different effects on their life. Based on evidence negative affect such depression associated with an increase risk of developing heart disease in a sample of healthy men.

Researchers believe that emotional symptoms of depression may cause emotional dysregulation. The suppression of emotion regulation strategies in the disorder. Patients with depression reported an increase suppression of negative affect not only repression but also for its positive affects, too is used. ${ }^{(30)}$

\section{Competing interests}

The authors declare that they have no competing interests.

\section{References}

1. Rozanski A, Blumenthal JA, Davidson KW, Saab PG, Kubzansky L. The epidemiology, pathophysiology, and management of psychosocial risk factors in cardiac practice: the emerging field of behavioral cardiology. J Am Coll Cardiol. 2005;45(5):637-51.

2. Fars news. Heart disease cause $38 \%$ death of Iran. No: 850701512

3. Syme SL. The social environment and health. In : Honda Foundation Discoveries Symposium: prosperity and well being. Toronto: Daedalus, Cambridge; 1993.

4. Marmot M, Winkelstein W Jr. Epidemiologic observations

* Published without substantive editing per OFAC guidance. 
on intervention trails for prevention of coronary heart disease. Am J Epidemiol. 1975;101(3):177-81.

5. Goldestein MG, Niaura R. Psychological factors affecting physical condition: Cardiovascular disease literature review. Part I: Coronary artery disease and sudden death. Psychosomatics. 1992;33(2):134-45.

6. Haines AP, Imeson JD, Meade TW. Phobic anxiety and ischaemic heart disease. Br Med J (Clin Res Ed). 1987;295(6593):297-9.

7. Kawachi I, Sparrow D, Vokonas PS, Weiss ST. Symptoms of anxiety and risk of coronary heart disease. The Normative Aging Study. Circulation. 1994;90(5):2225-9.

8. Eaker ED, Pinsky J, Castelli WP. Myocardial infarction and coronary death among women: psychosocial predictors from a 20-year follow-up of women in the Framingham study. Am J Epidemiol. 1992;135:854-64.

9. Karmarck T, Jennings JR. Biobehavioral factors in sudden cardiac death. Psychol Bull. 1991;109(1):42-75.

10. Scheniderman N. Psychophysiologic factors in atherogensis and coronary artery disease. Circulation. 1987;76(1 Pt 2):141-7.

11. McCollam JB, Burish TG, Maisto SA, Sobell MB. Alcohol's effects on physiological arousal and self-reported affect and sensations. J Abnorm Psychol. 1980; 89(2):224-33. 12. Gross JJ. Antecedent-and response-focused emotion regulation: divergent consequences for experience, expression, and physiology. J Pers Soc Psychol. 1998;74(1):224-37.

13. Thompson RA. Emotion regulation: a theme in search of definition. Monogr Soc Res Child Dev. 1994;59(2-3):25-52.

14. Garnefski N, Van den Kommer T, Kraaij V, Teerds J, Legerstee J, Onstein E. The relationship between cognitive emotion regulation strategies and emotional problems: comparison between a clinical and a non-clinical sample. Eur J Pers. 2002;16:403-20.

15. Gross JJ. Antecedent- and response-focused emotion regulation: divergent consequences for experience, expression, and physiology. J Pers Soc Psychol. 1998;74(1):224-37.

16. Frijda NH. The laws of emotion. Am Psychol. 1988;43(5):349-58.

17. Gross JJ, Levenson RW. Emotional suppression: physiology, self-report, and expressive behavior. J Pers Soc Psychol. 1993;64(6):970-86.

18. Speisman JC, lazarus RS, Mordkoff A, Davison L. Experimental reduction of stress based on ego-defense theory.
J Abnorm Psychol. 1964;68:367-80.

19. Gross JJ. The emerging field of emotion regulation: An integrative review. Rev Gen Psychol. 1998;2:271-99.

20. Werrner K, Gross JJ. Emotion regulation and Psychopathology: A conceptual framework. In Kring AM, Slaon DM, editors. Emotion Regulation and Psychopathology: A Transdiagnostic Approach to Etiology and Treatment. Guilford Press; 2007:89-92.

21. Gross JJ, John OP. Individual differences in two emotion regulation processes: Implications for affect, relationships, and well-being. J Pers Soc Psychol. 2003;85(2):348-62.

22. Gross JJ, Thompson RA. Emotion regulation: Conceptual foundations. In Gross JJ, editor. Handbook of emotion regulation. New York: Guilford; 2007:3-24.

23. Rasmussen K, Ravnsbaek J, Funch-Jenson P, Bagger JP. Oesophageal spams in patients with coronary artery spam. Lancet. 1986;1(8474)174-6.

24. Davies MJ, Thomas A. Thrombosis and acute coronaryartery lesions in sudden cardiac ischemic death. N Engl J Med. 1984;310(18):1137-40.

25. Hofmann SG, Heering S, Sawyer AT, Asnaani A. How to handle anxiety: The effects of reappraisal, acceptance, and suppression strategies on anxious arousal. Behav Res Ther. 2009;47(5):389-94. doi: 10.1016/j.brat.2009.02.010.

26. Haga SM, Kraft P, Corby EK. Emotion regulation: antecedents and well - being outcomes of cognitive reappraisal and expressive suppression in cross-cultural samples. J Happiness Studies. 2009;10:271-29.

27. Memedovic S, GrishamJ, DensonT, Moulds M. The effects of trait reaapraisal and suppression on anger and blood pressure in response to provocation. J Res Pers. 2010;44:540-54.

28. Mauss IB, Cook CL, Cheng JYJ, Gross JJ. Individual differences in cognitive reappraisal: experiential and physiological responses to an anger provocation. Int $\mathrm{J}$ Psychopathol. 2007;66(2):116-124.

29. Meyer T, Smeets T, Giesbrecht T, Merckelbach H. The efficiency of reappraisal and expressive suppression in regulating everyday affective experiences. Psychiatry Res. 2012; 200(2-3):964-9. doi: 10.1016/j.psychres.2012.05.034.

30. Beblo T, Fernando S, Klocke S, Griepenstroh J, Aschenbrenner S, Driessen M. Increased suppression of negative and positive emotions in major depression. J Affect Disord. 2012;141(2-3):474-9. doi: 10.1016/j. jad.2012.03.019. 